\title{
Validity and reliability of a physical activity/inactivity questionnaire in South African primary schoolgirls
}

\author{
Z J Mciza (BSc Dietetics) ${ }^{1}$ \\ J H Goedecke (PhD) $)^{1,2}$ \\ E V Lambert (PhD) $)^{1}$ \\ ${ }^{1}$ UCT/MRC Research Unit for Exercise Science and Sports Medicine, Department of Human Biology, Faculty of Health Sciences, University of \\ Cape Town \\ ${ }^{2}$ Medical Research Council of South Africa, Parow, Cape Town
}

\begin{abstract}
Objective. We sought to determine the validity and reliability of a self-report physical activity questionnaire (PAQ) measuring physical activity/inactivity in South African schoolgirls of different ethnic origins.

Methods. Construct validity of the PAQ was tested against physical activity energy expenditure estimated from an ACTIVITYGRAM and inactivity from reported television programme viewing in 332 girls (ages 9 - 12 yrs, grades 4 - 5). Body composition (WHO BMI percentiles and percentage body fat) was used as an indirect measure of validity for the PAQ. Test-retest reliability of the PAQ was assessed in a convenience sample of 14 girls.

Results. Weak but significant associations were found between the body composition and PAQ-derived total energy expenditure $(r=-0.18 ; p<0.05$ for percentage body fat; $r=-0.17 ; p<0.01$ for WHO BMI percentiles) and inactivity $(r=0.35 ; p<0.001$ for percentage body fat; $r=0.23$; $p<0.001$ for WHO BMI percentiles). Positive associations were found between moderate and vigorous energy expenditure by $P A Q$ and the same intensity activities by ACTIVITYGRAM ( $r=0.19 ; p<0.001$ and $r=0.26 ; p<0.001$, respectively). Further, the television viewing time reported
\end{abstract}

\section{CORRESPONDENCE:}

Professor Estelle V Lambert

UCT/MRC Research Unit for Exercise Science and Sports Medicine

Department of Human Biology

Faculty of Health Sciences

University of Cape Town

PO Box 115

Newlands 7725

Tel/fax: (021) 650-4571/686-7530

E-mail: vicki.lambert@uct.ac.za by $P A Q$ was significantly positively related to the number of programmes noted from the television programme list. Only total energy expended while partaking in structured school sports showed good test-retest reliability $(r=0.80$; $p<0.05)$.

Conclusions. Our results showed that the PAQ may provide some reasonable insights into levels of physical inactivity and activity in South African primary schoolgirls. However, additional studies are required using objective measures of physical activity, such as pedometry or accelerometry, to better understand the utility of the PAQ for children.

\section{Introduction}

Overweight and obesity in children is becoming a global problem, with an increasing prevalence among children of all age groups. ${ }^{54}$ South African children are no exception, with a prevalence of overweight and obesity of $14.0 \%$ and $3.2 \%$ in boys, respectively. In girls between the ages of 6 and 13 years, $17.9 \%$ are overweight and a further $4.9 \%$ are obese. ${ }^{5}$ Studies performed on small, local and regional samples of South African children suggest that the relatively high prevalence of obesity may be attributed in part to a decline in habitual physical activity, an increase in inactivity and sedentary lifestyles, associated with increasing urbanisation and improved socioeconomic status within households (assessed by the reliance on motorised transport). $8,13,19,27,32$ Indeed, it has been reported that children with lower levels of lean body mass and higher body mass index (BMI) are spending more time watching television or using computers, instead of engaging in physical activity, sports or play. $3,12,15,27,39,53$ Moreover, a national study undertaken in South African adolescents suggests that only $54.3 \%$ have physical education classes on their timetable, and of these only $52.8 \%$ engage in vigorous activity during class. ${ }^{33}$ Physical activity in childhood tracks into adulthood, thereby emphasising the need to address the lack of physical activity in children and youth. $^{10,20,43,45}$

An accurate measurement of physical activity is fundamental to our understanding of the relationships 
between physical activity, obesity and health. ${ }^{15,41}$ There are a myriad of international studies using self-report questionnaires (including both previous-day and 7day physical activity recalls) in children in which both construct and criterion validity and reliability have been tested. ${ }^{1,4,18,37,40,42,44,52}$ Ideally, an instrument should capture all aspects of physical activity including physical activity during and after school as well as sedentary behaviour, and be able to differentiate between weekday and weekend physical activity. ${ }^{24}$

However, there is a lack of locally validated instruments for this purpose in South Africa, and as a result, a paucity of data concerning the prevalence of physical activity in South African children. Therefore, the main aim of our study was to validate a self-report method of estimating physical activity/ inactivity levels in South African children. The method needed to be culturally sensitive, cost effective, and convenient to administer in larger groups of children, as part of formative assessment for intervention studies to increase physical activity.

For the purpose of this study, a physical activity questionnaire (EPAQ2), used to assess physical activity in European adolescents, ${ }^{49}$ was modified and adapted to estimate physical activity/inactivity in a group of preadolescent South African children of different ethnic origins. ${ }^{28}$ Construct validity and reliability of this modified and adapted physical activity questionnaire (PAQ) were then tested against an ACTIVITYGRAM and a television programme list, and the body composition of the girls was used as an indirect measure of validity of the PAQ.

\section{Methods}

\section{Subjects}

This validation study was undertaken as part of a larger project in which diet and physical activity, knowledge, attitudes, beliefs and health behaviours in South African women and their daughters were evaluated. ${ }^{26}$

Girls (ages 9 - 12 yrs, grades 4 - 5, N=332) were recruited from 15 primary schools in the Cape Town metropole area, sampled on the basis of divergent socioeconomic status (represented by low, middle and high socioeconomic strata). Thirty per cent of girls interviewed were from schools within the highest socioeconomic strata, $49 \%$ from the middle socioeconomic strata and $21 \%$ from the lowest strata. The response rate for the girls was $89 \%$. The final sample comprised $32 \%$ black girls, $34 \%$ mixed ancestry girls and $34 \%$ white girls. A convenient sample of 14 girls with similar characteristics to the main sample was randomly selected, and the questionnaire was re-administered 1 week later in an effort to perform the test-retest analysis (reliability) of the questionnaire.

\section{Body composition measures}

As an indirect measure of validity of the PAQ, body composition was measured using BMI, World Health Organization body mass index (WHO BMI) percentiles, as well as percentage body fat. $3,16,17$

BMI was calculated as $\mathrm{kg} \cdot \mathrm{m}^{-2}$ (body weight was assessed in light clothing, without shoes, and recorded to the nearest $0.5 \mathrm{~kg}$ using a calibrated digital scale (Tanita HD-309, Tanita Corporation of America Inc, USA). Body weight was then divided by the height squared, which was measured to the nearest $0.5 \mathrm{~cm}$ ). WHO BMI percentiles were also determined. ${ }^{9}$ Triceps, biceps, subscapular and supra-iliac skinfold thicknesses were measured using calibrated skinfold calipers (Harpenden, ASSIST creative resources Ltd, UK), and recorded to the nearest $0.1 \mathrm{~mm}$. Percentage body fat was calculated using standard equations. ${ }^{11}$

\section{Instruments}

Physical activity/inactivity over a period of 7 days was assessed using a PAQ adapted from the EPAQ2, ${ }^{49}$ which had previously been successfully used in a younger group of South African children ( 7 - 9-yr-olds). ${ }^{28}$ The PAQ included questions on physical education classes, formal and informal activities, activities done at school, activities done out of school in sports clubs or gyms, as well as just playing games at home. The girls were also required to report on hours spent walking to and from school, or just simply sitting and using a computer or watching television. The PAQ was administered by trained interviewers, who conducted the interviews using the language of choice for each of the 332 girls. The PAQ was then re-administered a week later on a convenience sample of 14 girls.

The total minutes spent doing physical activity as measured by the PAQ were converted to energy expenditure in the form of MET min.week ${ }^{-1}$, by multiplying the minutes per week by different levels of intensities. These levels of intensity were defined as: resting (1 METs), light (3.0 METs), moderate (4.5 METs) and vigorous (7.5 METs). ${ }^{2,22}$

Physical inactivity was quantified on the basis of television or computer time per week. Furthermore, girls completed the ACTIVITYGRAM developed by the Cooper Institute (Dallas, Texas, USA) ${ }^{51}$ in which they were required to rate the intensity of their activities during 30-minute time intervals throughout the day. They were also asked to mark the television programmes watched from a pre-prepared list, as well as the frequency and duration of watching television in an average week. These results were based on a television programme list, which included the most commonly watched programmes by South African children.

\section{Statistical analysis}

All data were analysed using Statistica version 7: (StatSoft Inc, Tulsa, OK, USA version 7.0). Data were reported as means \pm standard deviations and $p<0.05$ was considered statistically significant. Where data were not normally distributed, medians, 25th and 75th quartiles were reported and non-parametric analyses were performed. Construct validity was determined using Spearman's rank-order correlations comparing results of the ACTIVITYGRAM with those of the 
self-report PAQ. Furthermore, the test-retest reliability was also evaluated using Spearman's rank correlation. Analysis of variance or Kruskal Wallis tests were performed to determine the differences in physical activity/inactivity between the three ethnic groups of girls. Where appropriate, Scheffe's post-hoc tests were used to evaluate between-group differences. In addition, between-group differences were adjusted for differences in socioeconomic status on the basis of housing density and asset index, using analysis of covariance. Chi-square analysis was used to determine ethnic differences in sociodemographic characteristics of the girls, as well as the categorical variables relating to physical activity derived from the PAQ.

\section{Results}

\section{Participants' characteristics}

Detailed characteristics of the participants have been reported previously. ${ }^{26}$ In brief, 332 girls participated in this study. The average age of the girls was $10.5 \pm 0.9,10.1 \pm 0.7$ and $10.0 \pm 0.8$ years, $p<0.001$, for black, mixed ancestry and white girls, respectively. Mean WHO BMI percentile was significantly higher in the white girls, compared with those of mixed ancestry and of African descent $(61 \pm 28$ v. $59 \pm 30$ and $57 \pm 31$ percentile, $p<0.05$, respectively). However, there were no significant differences in the body weight, height and body fatness between the girls. Black girls presented with significantly lower socioeconomic status based on the housing density and asset index, than the other groups of girls $(p<0.001)$. In addition, fewer black girls reported having television (77 v. 99 and $98 \%, p<0.001$, respectively) or computers (16 v. 77 and $87 \%, p<0.001$, respectively) in their households, as well as having physical education offered at their schools (63 v. 88 and 93\%, $p<0.001$, respectively) compared with mixed ancestry and white girls. The characteristics of the sub-group sampled for test-retest reliability $(N=14)$ were not significantly different than those of the larger group $(N=332)$ (data not shown).

\section{Body composition as an indirect measure of PAQ validity}

Body composition (WHO BMI percentiles and percentage body fatness) of the girls was used as an indirect measure of the validity of PAQ-derived measures of energy expenditure and inactivity (Table I). Weak but significant inverse associations were found between the girls' percentage body fat and total energy expenditure and inactivity by PAQ. Furthermore, there was an inverse association between girls' WHO BMI percentiles and moderate energy expenditure derived from walking to and from school.

\section{Construct validity of PAQ against the ACTIVITYGRAM and television programme list}

Construct validity of the PAQ-derived measures of energy expenditure and inactivity against energy expenditure derived from the ACTIVITYGRAM and from the television programme list are presented in Table II. A significant positive association was found between the time spent watching television, recorded in the PAQ, and the number of television programmes selected from the television list. Weak but significant positive associations were also found between moderate and vigorous energy expenditure by the PAQ and the same intensity activities recorded using the ACTIVITYGRAM. However, no significant associations were observed in overall $P A Q-$ derived energy expenditure and total energy expenditure estimated using an ACTIVITYGRAM.

\section{Test-retest reliability of the PAQ}

We were only able to demonstrate significant test-retest reliability for total energy expenditure (MET min.week ${ }^{-1}$ ) for the structured school sports $(r=0.79, p<0.05)$. The remainder of

TABLE I. Indirect validity of the physical activity questionnaire (PAQ)-derived measures of energy expenditure and inactivity against body composition of the girls

WHO BMI percentiles v. overall energy expenditure

Percentage body fat $v$. overall energy expenditure

WHO BMI percentiles v. moderate energy expenditure (walking to and from school)

WHO BMI percentiles $v$. overall television time

Percentage body fat $v$. overall television time

$\begin{array}{ll}\text { Spearman's } \rho & \boldsymbol{p} \\ -0.18 & <0.05 \\ -0.17 & <0.01 \\ -0.17 & <0.01 \\ 0.23 & <0.001 \\ 0.35 & <0.001\end{array}$

TABLE II. Construct validity of the physical activity questionnaire (PAQ)-derived measures of energy expenditure and inactivity against the ACTIVITYGRAM and television programme list

\begin{tabular}{|c|c|c|}
\hline & Spearman's $\rho$ & $p$ \\
\hline Moderate energy expenditure by the PAQ v. moderate energy expenditure by an ACTIVITYGRAM & 0.19 & $<0.001$ \\
\hline Vigorous energy expenditure by the PAQ v. vigorous energy expenditure by an ACTIVITYGRAM & 0.26 & $<0.001$ \\
\hline Overall energy expenditure by the PAQ v. total energy expenditure by an ACTIVITYGRAM & 0.02 & 0.78 \\
\hline Television time by the PAQ $v$. number of programmes watched by the television programme list & 0.19 & $<0.001$ \\
\hline
\end{tabular}


the PAQ physical activity constructs did not show good test-retest reliability over a period of 7 days (Table III).

\section{Ethnic differences in energy expenditure}

Ethnic differences in energy expenditure estimated using the PAQ and ACTIVITYGRAM are presented in Table IV. Although none of the black girls participated in physical activity outside of school in sports clubs, they reported expending more overall energy per week than white and mixed ancestry girls $(p<0.001)$. Most of this energy was expended while partaking in moderate physical activity at school $(p<0.001)$ and informal game activities at home $(p<0.001)$. There was an inverse association between socioeconomic status (presented by housing density and asset index) and energy expenditure $(r=-0.18, p<0.05$ and $r=-0.26, p<0.05$ respectively). Black girls expended more total energy than mixed ancestry and white girls even after adjusting for the confounding factors of socioeconomic status based on both the housing density and asset index (both $p$ values $<0.05$ ) (data not shown). In addition, the majority of black girls reported expending more energy by walking to and from school than mixed ancestry and white girls (73 v. 16 and $11 \%$, respectively, $p<0.001$ ). However, no significant ethnic differences were found in energy expenditure generated using the ACTIVITYGRAM even after adjusting for socioeconomic status. Only ethnic differences in vigorous activities tended towards significance $(p=0.057)$.

\section{Ethnic differences in inactivity}

Table $\mathrm{V}$ presents the time spent by the girls using technology-based entertainment (watching television and using a computer) each day. Using the PAQ, we found that overall, mixed ancestry girls were more likely to use technology-based entertainment than white and black girls $(p<0.05)$. However, white girls spent significantly more time watching television than mixed ancestry and black girls $(p<0.05)$. White girls spent most of this time on weekends $(p<0.05)$. Ethnic differences in television time remained the same even after adjusting for socioeconomic status based on housing density. Further, the girls who watched 3 or more hours of television each day had greater mean WHO BMI percentiles than those who watched less than 3 hours of television per day (61.2 \pm 29.0 v. $54.4 \pm 30.5$, percentiles, $p<0.05$ (Fig. 1)). However, no ethnic differences were found. The relationship between WHO BMI percentiles and television hours was unaltered by socioeconomic status (as presented by both the housing density and asset index scores). The

TABLE III. Test-retest reliability of the energy expenditure and inactivity measured by the physical activity questionnaire (PAQ)

\begin{tabular}{lrr} 
School sports (minutes/week) & 0.79 & $<0.05$ \\
Home games (minutes/week) & -0.50 & 0.67 \\
Club/gym sport (minutes/week) & -0.37 & 0.30 \\
Television time (minutes/week) & 0.27 & 0.35 \\
Moderate activity (MET minutes/day) & 0.06 & 0.27 \\
Vigorous activity (MET minutes/day) & -0.33 \\
Overall activity (MET minutes/day) & -0.20 & 0.63 \\
\hline
\end{tabular}

TABLE IV. Girls' energy expenditure according to ethnicity measured by the physical activity questionnaire (PAQ) and the ACTIVITYGRAM

\begin{tabular}{|c|c|c|c|}
\hline Level of activity & $\begin{array}{l}\text { Black } \\
32 \%(N=105)\end{array}$ & $\begin{array}{l}\text { Mixed ancestry } \\
34 \%(N=113)\end{array}$ & $\begin{array}{l}\text { White } \\
34 \%(N=114)\end{array}$ \\
\hline \multicolumn{4}{|c|}{ PAQ school (MET min/week) } \\
\hline Moderate & $360(0 ; 1800)$ * & $0(0 ; 720) * \dagger$ & $720(0 ; 1080) \dagger$ \\
\hline Vigorous & $0(0 ; 0)^{*}$ & $0(0 ; 0) \dagger$ & $0(0 ; 480)^{*} \dagger$ \\
\hline Total & $720(0 ; 1800)^{*} \dagger$ & $480(0 ; 1080)^{*}$ & $810(420 ; 1620) \dagger$ \\
\hline \multicolumn{4}{|c|}{ PAQ overall (MET min/week) } \\
\hline Moderate & $720(0 ; 2520)$ & $540(0 ; 1080)^{*}$ & $720(360 ; 1440)^{*}$ \\
\hline Vigorous & $0(0 ; 960)^{*}$ & $120(0 ; 960)$ & $480(0 ; 1440)^{*}$ \\
\hline Total & $2528(1080 ; 4950)^{\star *}$ & $1295(660 ; 2400)^{* *} \dagger$ & 2 106(1040;3 100) † \\
\hline \multicolumn{4}{|c|}{ ACTIVITYGRAM (MET min/week) } \\
\hline Moderate & $3360(840 ; 4200)$ & $1680(0 ; 5040)$ & $0(2520 ; 5040)$ \\
\hline Vigorous & $0(0 ; 3360)$ & $0(0 ; 0)$ & $0(0 ; 0)$ \\
\hline Total & $7560(4$ 830;10 500) & $6300(3360 ; 9660)$ & $620(3360 ; 11$ 130) \\
\hline
\end{tabular}


TABLE V. Girls' physical inactivity according to ethnicity measured by the physical activity questionnaire (PAQ) and the television programme list

\begin{tabular}{|c|c|c|c|}
\hline Levels of inactivity & Black & Mixed ancestry & White \\
\hline \multicolumn{4}{|c|}{ PAQ television time (min/day) } \\
\hline Weekday & $80(0 ; 120)^{*}$ & $100(15 ; 180)$ & $120(25 ; 200)^{*}$ \\
\hline Weekend & $160(0 ; 260)^{*}$ & $180(35 ; 300) \dagger$ & $240(30 ; 350)^{*} \dagger$ \\
\hline Total & $240(0 ; 380)^{*}$ & $210(30 ; 420)^{* * *}$ & $270(30 ; 450)^{\star *}$ \\
\hline \multicolumn{4}{|c|}{ PAQ technology-based entertainment (sum of television and computer time, min/day) } \\
\hline Total & $240(180 ; 480)^{*}$ & $480(300 ; 600)^{* * *}$ & $300(180 ; 540)^{* *}$ \\
\hline \multicolumn{4}{|c|}{ Television programme list (television time, $\mathrm{min} /$ day) } \\
\hline Total & $36(18 ; 81)^{* * *}$ & $75(78 ; 105)^{*} \ddagger$ & $78(51 ; 129)^{\star *} \ddagger$ \\
\hline
\end{tabular}

time spent watching television each day decreased with a decrease in socioeconomic status based on the housing density $(r=-0.12, p<0.05)$. Significant ethnic differences generated using the television programme list are also presented in Table $\mathrm{V}(p<0.05)$. These differences also remained unaltered even after adjusting for socioeconomic status $(p<0.05)$.

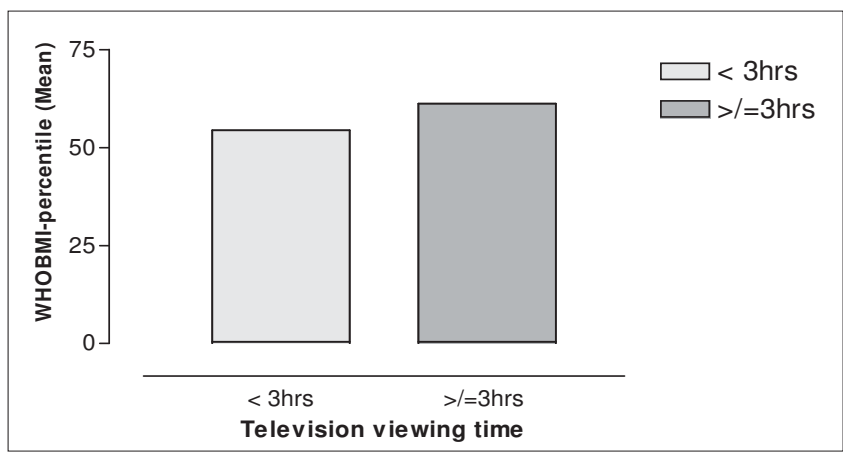

Fig. 1. The WHO BMI percentiles of the girls who reported watching less than 3 hours of television compared with those who reported watching 3 or more hours of television each day. Mean WHO BMI percentile of girls who reported watching $\geq 3$ hours of television was higher than those girls who watched $<3$ hours of television each day $(p<0.05)$.

\section{Discussion}

Energy expenditure in the form of physical activity is associated with well-established health benefits, ${ }^{14,25,30}$ which increase with an increase in frequency, duration and intensity of exercise. ${ }^{47}$ However, a more detailed understanding of the required exercise dosage and the extent of resulting health benefits is required, particularly in children where inactivity and the prevalence of obesity are increasing at an alarming rate. $^{5}$ This may only be achieved through the development of standardised instruments that record the low-intensity activities typical of sedentary societies, and ascribe consistent biological meaning to terms such as light, moderate, and heavy exercise. ${ }^{41,45}$ However, there are few validated instruments that measure physical activity and inactivity that are pertinent to multicultural and developing countries such as South Africa, where there is a high prevalence of overweight and obesity in children. ${ }^{5}$ In the present study, an adapted version of a PAQ previously used in South African children ${ }^{28}$ and European adolescents ${ }^{49}$ demonstrated only modest indirect criterion validity, concurrent and construct validity in South African primary schoolgirls.

Based on evidence suggesting an association between body composition and physical activity/inactivity, ${ }^{3,16,17}$ we used measures of body fatness and WHO BMI percentiles as indirect measures of validity for $P A Q$-derived energy expenditure and inactivity. In this study, body fatness and WHO BMI percentiles were lower in those girls with higher overall energy expenditure (generated by partaking in sports or play, and walking to and from school), and those girls who spent less time watching television. These results are in agreement with other local and international studies. ${ }^{27,34,42}$ Indeed, we found that watching television for 3 hours was associated with increased WHO BMI percentiles levels, in agreement with other South African studies undertaken on local samples of children. ${ }^{7,21,27}$ Further, in the current study, the majority of black girls reported expending more energy by walking to and from school than those of mixed ancestry and white girls. Similarly, the reliance on motorised vehicles for transport has been associated with a decline in physical activity, linked to weight gain. 3,12,15,39,53

PAQ also showed comparable construct validity for inactivity when compared with inactivity generated by the television programme list. However, the total time spent by the girls watching television each day generated by the PAQ, was more than three times that generated using the television programme list. The use of the television programme list might have underestimated inactivity as it may have overlooked other programmes watched in conjunction with adults. Moreover, due to programmes constantly changing, some of the programmes in the list were no longer featured on television. Conversely, systemic error (or bias) may have resulted in an over-estimation of minutes spent watching television per day when television watching was recalled over the past week using the PAQ. Indeed, Ridley (2005) 
demonstrated that asking 'How many minutes of television did you watch the previous week?, ${ }^{35}$ resulted in an overestimation of the total time of inactivity compared with when television watching was capped within a 24-hour time frame. Ridley suggested that such an error can be reduced by rephrasing the question and making it simpler. Indeed, the television programme list was simpler and possibly made recalling easier.

Nonetheless, both the PAQ and the television programme list managed to identify significant ethnic differences in inactivity, such that black girls spent less time watching television than girls of mixed ancestry and white girls. These ethnic differences remained significant, even after adjusting for housing density and asset index, which were also significant correlates of television watching time. In contrast, McVeigh et al. found that white children were more active and watched less television than black children. ${ }^{27}$ However, in their study they found no differences in socioeconomic status between ethnic groups, whereas the black participants in the current study presented with lower socioeconomic status compared with mixed ancestry and white girls, which may explain the differences between studies.

Further, the PAQ showed comparable construct validity for moderate and vigorous activities compared with the ACTIVITYGRAM. However, the total ACTIVITYGRAM energy expenditure was almost double that of the PAQ. A possible explanation for these differences can be the underestimation of energy expenditure by PAQ brought about by memory decay when asking the children to recall their activities over the past 12 months, which may lead to systemic error or bias in reporting. There is evidence to suggest that children might have difficulty in recalling activities that they participated in within the time frame of 12 months. ${ }^{35,36}$ Thus rephrasing and simplifying the questionnaire to ask the children about the minutes they spent in activity on the previous day, on a number of occasions, is generally recommended. In contrast, the ACTIVITYGRAM asked the girls to recall their activities the previous day from the time they woke up in the morning, until the time they went to bed (from $7 \mathrm{am}$ to $10: 30 \mathrm{pm}$ ). ${ }^{48}$ Despite differences in absolute energy expenditure, we found a weak but significant positive relationship between the two measures, which is in agreement with other similar international studies. ${ }^{37,38,46,50,51}$ These studies argue that when using complex and lengthy questionnaires children become bored, which may negatively impact the instrument's validity, yielding weak Spearman's $\rho$. This validation study was undertaken as part of a larger project, during which the girls were also asked questions on their diet and physical activity knowledge, attitudes, beliefs and health behaviours. This may have contributed to the respondent burden, thereby increasing fatigue and boredom during the interviews, which may have impacted on the quality of the relationships we obtained.

In this study we further observed significant ethnic differences in PAQ energy expenditure and a trend for ethnic differences in energy expenditure using the ACTIVITYGRAM.
Black girls had the highest energy expenditure, followed by white girls and lastly the girls of mixed ancestry. Higher levels of activity in the black girls could possibly be attributed to their lower socioeconomic status, measured by the asset index and household density. Indeed, Monyeki and associates found that where space is limited and there is overcrowding, children will spend more of their time playing unstructured and informal activities away from home. ${ }^{29}$ Participation in play sport has previously been associated with increased energy expenditure. ${ }^{39,53}$

Finally, this study showed reasonable test-retest reliability of the PAQ only for structured school sports. This can be explained by the fact that girls of this age ( $9-12$ years) can recall and report participation in structured school sports well, compared with other unstructured game sports played at home and at school or in sports clubs. These unstructured activities may vary from time to time due to the school term (such as writing exams, weather or seasonal changes). 4,23,31,47 Furthermore, memory decay has been reported in other international studies in children, where it was found that children under the age of 10 could with reasonable accuracy recall the activity from the previous day, but had great difficulty with days further back in time..$^{4,6,47}$ The majority (69\%) of our participants were 10 years and younger, a factor that would therefore influence the reliability of the activity recall after 7 days.

\section{Conclusion}

Despite the relatively weak associations between the PAQderived energy expenditure and inactivity, against those derived from the ACTIVITYGRAM-derived energy expenditure and television-derived time spent in sedentary behaviour, we found that the PAQ may be useful in characterising the physical activity levels and patterns of the South African children of varying socioeconomic background. The PAQ shows a potential in highlighting health benefits associated with adoption of physical activity, such as reduced body fatness and BMI levels. Further, its usefulness in quantifying energy expenditure has been highlighted, such that it is able to distinguish between the intensity levels of the activity, by identifying moderate and vigorous energy expenditure in South African schoolgirls.

It also enables us to quantify and distinguish energy expenditure generated by activities performed at school, out of school, formal and informal, with the more formal activities showing good reliability. Further, it quantifies time spent in sedentary behaviours such as watching television, using computers, relying on motorised vehicle for transport, and identifies whether physical education is included in the school curriculum and if children are participating. Indeed, the strength of association is comparable with those observed in similar studies where validation of self-administered questionnaires was tested in children. ${ }^{18,35,37,51}$ Studies suggest that validity may be improved by making questionnaires simpler and only asking about children's activity over a 24-hour period. 
Another approach is for researchers to make use of objective physical activity measures instead of questionnaires. Further evidence suggests that choosing a suitable measure of physical activity/inactivity for children is often a trade-off between accuracy, depth of information gathered, cost and subject and researcher burden.

Information provided by such questionnaires is relevant for South Africa, where inactivity and the prevalence of obesity in children are becoming an important public health issue. However, additional studies are required using objective measures of physical activity, such a pedometry or accelerometry, to better understand the utility of the PAQ for children.

\section{Acknowledgements}

This study was funded by the Nestlé Foundation, the Medical Research Council of South Africa, the University of Cape Town, the South African Department of Science and Technology and the National Research Foundation (scholarship for Z Mciza). Gratitude is extended to all the principals, parents and learners in the Cape Town metropole primary schools in which the study was conducted. Nasreen Jaffer, Lauren Hill, Madalaine Carstens, Alicia Hess are thanked for their assistance with data collection and their technical assistance.

\section{REFERENCES}

1. Aaron DJ, Kriska AM, Dearwater SR, Cauley JA, Metz KF, LaPorte RE. Reproducibility and validity of an epidemiologic questionnaire to assess past year physical activity in adolescents. Am J Epidemiol 1995; 142: 191-201.

2. Ainsworth BE, Haskell WL, Leon AS, et al. Compendium of physical activities: classification of energy costs of human physical activities. Med Sci Sports Exerc 1993; 25: 71-80.

3. Andersen RE, Crespo CJ, Bartlett SJ, Cheskin LJ, Pratt MD. Relationship of physical activity and television watching with body weight and level of fatness among children: Results from the Third National Health and Nutrition Examination Survey. JAMA 1998; 279: 938-42.

4. Argiropoulou EC, Michalopoulou M, Aggeloussis N, Andreas A. Validity and reliability of physical activity measures in Greek high school age children. $J$ Sports Sci Med 2004; 3: 147-59.

5. Armstrong ME, Lambert MI, Sharwood KA, Lambert EV. Obesity and overweight in South African primary school children - the Health of the Nation Study. S Afr Med J 2006; 96: 439-44.

6. Baranowski T. Validity and reliability of self report measures of physical activity: an information-processing perspective. Res Q Exerc Sport 1988; 59: 314-27.

7. Bourne LT, Lambert EV, Steyn K. Where does the black population of South Africa stand on the nutrition transition? Public Health Nutr 2002; 5: 157-62.

8. Cameron N. Physical growth in a transitional economy: the aftermath of South African apartheid. Econ Hum Biol 2003; 1: 29-42.

9. Cole TJ, Bellizzi MC, Flegal KM, Dietz WH. Establishing a standard definition for child overweight and obesity worldwide: international survey. BMJ 2000; 320: 1240-3.

10. Dennison BA, Strauss JH, Mellits ED, Charney E. Childhood physical fitness tests: predictor of adult physical activity levels? American Academy of Pediatrics 1998; 82: 324-30.

11. Durnin JV, Womersley J. Total body fat, calculated from body density, and its relationship to skinfold thickness in 571 people aged $12-72$ years. Proc Nutr Soc 1973; 32(1):45A.

12. Eisenmann JC, Bartee RT, Wang MQ. Physical activity, TV viewing, and weight in U.S. youth: 1999 Youth Risk Behavior Survey. Obes Res 2002; 10: $379-85$.
13. Goduka IN, Poole DA, Aotaki-Phenice A. A comparative study of black South African children from three different contexts. Child Dev 2007; 63: 509-25.

14. Goran MI, Reynolds KD, Lindquist $\mathrm{CH}$. Role of physical activity in the prevention of obesity in children. Int J Obes Relat Metab Disord 1999; 23: S18-33.

15. Hu FB, Stampfer MJ, Solomon C, et al. Physical activity and risk for cardiovascular events in diabetic women. Ann Intern Med 2001; 134: 96-105.

16. Hu FB, Willett WC, Li T, Stampfer MJ, Colditz GA, Manson JE. Adiposity as compared with physical activity in predicting mortality among women. $N$ Engl J Med 2004; 351(26): 2694-703.

17. Iqbal R, Rafique G, Badruddin S, Qureshi R, Gray-Donald K. Validating MOSPA questionnaire for measuring physical activity in Pakistani women. Nutr J 2006; 5:18.

18. Janz KF. Validation of the CSA accelerometer for assessing children's physical activity. Med Sci Sports Exerc 1994; 26: 369-75.

19. Kruger R, Kruger HS, Maclntyre UE. The determinants of overweight and obesity among 10- to 15-year-old schoolchildren in the North West Province, South Africa - - the THUSA BANA (Transition and Health during Urbanisation of South Africans; BANA, children) study. Public Health Nutr 2006; 9: 351-8.

20. Kuh DJ, Cooper C. Physical activity at 36 years: patterns and childhood predictors in a longitudinal study. J Epidemiol Community Health 1992; 46: 114-9.

21. Lambert EV, Lambert MI, Hudson $\mathrm{K}$, et al. Role of physical activity for health in communities undergoing epidemiological transition. World Rev Nutr Diet 2001; 90: 110-26.

22. Lohman TG. Exercise training and body composition in childhood. Can J Sport Sci 1992; 17: 284-7.

23. Matthews CE, Hebert JR, Freedson PS, et al. Sources of variance in daily physical activity levels in the seasonal variation of blood cholesterol study. Am J Epidemiol 2001; 153: 987-95.

24. McCormack G, Giles-Corti B. The development of the Western Australian Incidental Physical Activity Questionnaire (WAIPAQ) and the assessment of motion sensors for measuring physical activity in Adults: Report to the Physical Activity Taskforce Evaluation and Monitoring Working Group. Department of Public Health: University of Western Australia. 2002.

25. McGinnis JM. The public health burden of a sedentary lifestyle. Med Sci Sports Exerc 1992; 24: S196-200.

26. Mciza Z, Goedecke JH, Steyn NP, et al. Development and validation of instruments measuring body image and body weight dissatisfaction in South African mothers and their daughters. Public Health Nutr 2005; 8: 509-19.

27. McVeigh JA, Norris SA, de Wet T. The relationship between socio-economic status and physical activity patterns in South African children. Acta Paediatr 2004; 93: 982-8.

28. Micklesfield L, Levitt N, Dhansay M, Norris S, van der Merwe L, Lambert E. Maternal and early life influences on calcaneal ultrasound parameters and metacarpal morphometry in 7- to 9-year-old children. J Bone Miner Metab 2006; 24: 235-42.

29. Monyeki KD, van Lenthe FJ, Steyn NP. Obesity: does it occur in African children in a rural community in South Africa? Int J Epidemiol 1999; 28: 287-92.

30. Pate RR, Pratt M, Blair SN, et al. Physical activity and public health. A recommendation from the Centers for Disease Control and Prevention and the American College of Sports Medicine. JAMA 1995; 273: 402-7.

31. Plasqui G, Westerterp KR. Seasonal variation in total energy expenditure and physical activity in Dutch young adults. Obes Res 2004; 12: 688-94.

32. Prista A, Maia AJ, Saranga S, Nhantumbo L, Marques AT, Beunen G. Somatic growth of a school-aged population from Mozambique: trend and biosocial meaning. Hum Biol 2005; 77: 457-70.

33. Reddy SP, Panday S, Swart D, Jinabhai CC, Amosun SL, James S Umthente Uhlaba Usamila - The South African Youth Risk Behaviour Survey 2002. Cape Town: South African Medical Research Council (2005, 9 November) Available from URL:http://www.mrc.ac.za/healthpromotion/reports.htm; 2003.

34. Rennie KL, Livingstone MB, Wells JC, et al. Association of physical activity with body-composition indexes in children aged 6-8 $y$ at varied risk of obesity. Am J Clin Nutr 2005; 82: 13-20.

35. Ridley K. The Multimedia Activity Recall for Children and Adolescents (MARCA): Development and validation. Doctoral thesis, University of South Australia, School of Health Sciences. 2005. 
36. Ridley K, Olds TS, Hill A. The Multimedia Activity Recall for Children and Adolescents (MARCA): development and evaluation. Int J Behav Nutr Phys Act 2006; 3: 10.

37. Sallis JF, Saelens BE. Assessment of physical activity by self-report: status, limitations, and future directions. Res Q Exerc Sport 2000; 71: S1-14.

38. Sallis JF, Prochaska JJ, Taylor WC. A review of correlates of physical activity of children and adolescents. Med Sci Sports Exerc 2000; 32: 963-75.

39. Salmon J, Ball K, Crawford D, et al. Reducing sedentary behaviour and increasing physical activity among 10-year-old children: overview and process evaluation of the 'Switch-Play' intervention. Health Promot Int 2005; 20: 7-17.

40. Sarkin JA, Nichols JF, Sallis JF, Calfas KJ. Self-report measures and scoring protocols affect prevalence estimates of meeting physical activity guidelines. Med Sci Sports Exerc 2000; 32: 149-56.

41. Shephard RJ. Limits to the measurement of habitual physical activity by questionnaires. Br J Sports Med 2003; 37: 197-206.

42. Stevens J, Suchindran C, Ring K, et al. Physical activity as a predictor of body composition in American Indian children. Obes Res 2004; 12: $1974-$ 80.

43. Telama R, Yang X, Viikari J, Valimaki I, Wanne O, Raitakari O. Physical activity from childhood to adulthood: A 21-year of tracking study. Am J Prev Med 2005; 28: 267-73.

44. Treuth MS, Sherwood NE, Butte NF, et al. Validity and reliability of activity measures in African-American girls for GEMS. Med Sci Sports Exerc 2003; 35: $532-9$

45. Vanreusel B, Renson R, Beunen G, et al. A longitudinal study of youth sport participation and adherence to sport in adulthood. International Review for the Sociology of Sport (IRSS) 1997; 32: 373-87.

46. Vuillemin A, Boini $S$, Bertrais $S$, et al. Leisure time physical activity and health-related quality of life. Prev Med 2005; 41: 562-9.

47. Wallace JP, McKenzie TL, Nader PR. Observed vs. recalled exercise behavior: A validation of a seven day exercise recall for boys 11 to 13 years old. Res Q Exerc Sport 1985; 56: 161-5.

48. Warburton DE, Nicol CW, Bredin SS. Health benefits of physical activity: the evidence. CMAJ 2006; 174: 801-9.

49. Wareham N J, Jakes, RW, Rennie KL, Mitchell J, Hennings S, Day NE. Validity and repeatability of the EPIC-Norfolk Physical Activity Questionnaire. Int J Epidemiol 2002; 31: 168-74.

50. Weiss TW, Sluiter CH, Green LW, Kennedy VC, Albright DL, Wun C. The validity of single-item, self assessment questions as measures of adult physical activity. J Clin Epidemiol 1990; 43: 1123-9.

51. Welk GJ, Dzewaltowski DA, Hill JL. Comparison of the computerized ACTIVITYGRAM instrument and the previous day physical activity recall for assessing physical activity in children. Res Q Exerc Sport 2004; 75: 37080.

52. Weston AT, Petosa R, Pate RR. Validation of an instrument for measurement of physical activity in youth. Med Sci Sports Exerc 1997; 29: 138-43.

53. Yackel EE. An activity calendar program for children who are overweight. Pediatr Nurs 2003; 29: 17-22.

54. York DA, Rossner S, Caterson I, et al. Prevention Conference VII: Obesity, a worldwide epidemic related to heart disease and stroke: Group I: worldwide demographics of obesity. Circulation 2004; 110: e463-70.

\section{CURRENT Diagnosis \& Treatment: Sports Medicine}

Author: Patrick J McMahon

August 9, 2006; Paperback; 624 pages

0071410635 / 9780071410632

\section{Readable. Comprehensive. Up-to-date. The one book to have for day-to-day answers in sports medicine.}

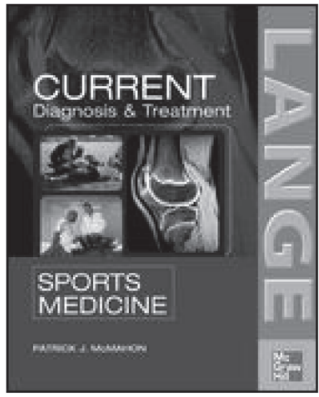

- Authoritative, point-of-care coverage with evaluation, treatment, and management of all common sports injuries

- Essential evidence-based stabilization and rehabilitation techniques

- Prevention strategies featured throughout

- Pre-participation and on-the-field evaluation

- Practical guidance on sports injuries in children

Coverage of the medical issues of female athletes

- In-depth treatment of concussion

- Up-to-date information on medical conditions and sports participation

- Numerous easy-to-read diagnostic charts, tables, and treatment graphs

- Concise, current, and comprehensive review of the biomechanics of sports medicine

- Helpful references to classic and important new sources

- Online updates at companion site CURRENTMED.COM 